\title{
The integrated geodetic monit oring system of open pit slopes in hard rock massifs
}

\author{
Anatolii Kozyrev ${ }^{1}$, Eduard Kasparian ${ }^{1}$ \& Ivan Rozanov ${ }^{1 *}$ \\ ${ }^{1}$ Mining Institute KSCRAS, 184209 Fersman str. 24, Apatity, Russia.
}

\begin{abstract}
The article describes an experience in organizing the integrated geomechanical monitoring in high-strength hard rock massifs using the longstanding GPS and optical distance measurements in the Zhelezny open pit, Kovdorsky GOK JSC, as well as measurements with the IBIS FM interferometric radar. The application of the integrated monitoring system in the Zhelezny open pit has allowed accumulation of significant statistical material, which made it possible to identify the patterns of the rock mass deformation development, determine the limiting parameters and develop several regulatory documents for observing and processing the measurement results of the benches and open pit walls displacements.
\end{abstract}

\section{Introduction}

The open mining of mineral deposits inevitably changes the geomechanical conditions of the geological environment, which is seen in the formation of new stress fields and deformations. As a result, open pits can be exposed to different-scaled rock failures, starting from rockfalls within one or several benches to significant shifts along the boundaries of structural blocks, extensive landslides and mining-induced induced earthquakes.

The mining operations often impact on residential and industrial facilities, the destruction of which can lead to severe consequences and the effects of mining-induced activity occur not only during the mining enterprise operation but also for a sufficiently long period after its liquidation.

To ensure the open pit slope and bench stability, it is necessary to obtain reliable information on changes in the rock mass state, as well as identify potentially unstable sections of the open pit. All of the aforesaid is impossible to carry out without the integrated geodetic monitoring system of the state of the rock mass.

An integrated monitoring system should contain monitoring methods that are appropriate for the specific geological, geomechanical and mining conditions of the deposit where this system will be applied.

\footnotetext{
*Corresponding author: ivan-rozanov@yandex.ru
} 


\section{Monitoring in soil and hard rock massifs}

A characteristic feature of the deposits development by open mining is a relatively high share of the near-surface, mostly weak rock layers, which often close to the soil rock massifs by its properties. The soil massifs differ small size of the constituent particles (within a few millimeters), very low adhesion between the particles, the almost complete lack of structural heterogeneities except stratification, and the presence of natural stress state caused solely by the gravitational field. As the open pit deepens, the share of soil rock mass reduces and the one of hard rock mass increases.

The hard rock masses have a pronounced hierarchical-block structure due to the extensive development of multiscale structural heterogeneities; their natural stress state is generally caused by gravitational tectonic stress fields.

In terms of geomechanics, open pit walls should be regarded as specific engineering structures, where different benches have a different lifetime. At that, the most long-lived upper benches are located in the most weakened soil rock masses where landslides are the most probable types of instability.

Hard rock benches, due to the hierarchical block structure, are weakened by structural heterogeneities with varying intensity, and the dominant geomechanical processes are the formation of border zones of disturbed rocks (zones of nonelastic deformations and failures), within which the separate rockfalls can occur.

Within the open pit wall, large-scale heterogeneities (weakened zones, geological failures, faults) determining the slope stability as a whole, can result in displacement of large structural blocks towards the mined-out space, as well as in landslides within the largest structural heterogeneities. Such a mechanism of rock deformations and failures in the hierarchical-blocked rock massifs determines the hierarchical structure of monitoring, in particular, its regional and local levels in terms of controlling the slope and bench stability.

The regional monitoring tasks include:

- observation of the rock mass deformation that contains the exploited deposit;

- zoning of the open pit into separate sections, according to the revealed nature of the rock mass deformation;

- reveal of potentially instable open pit areas;

The local monitoring tasks include:

- observation of identified potentially dangerous rock mass deformation areas;

- monitoring the state of a potentially dangerous area;

- forecasting the failure process development;

- analysis of causes, nature and parameters of rock deformation and failure.

As an example of the proposed methodology, we present an integrated monitoring system organized at the Kovdor complex magnetite-apatite-baddeleyite deposit, which rock mass has all the characteristic features of hard rock massifs.

\section{The integrated monitoring system of the Zhelezny open pit, Kovdorsky GOK JSC}

\subsection{The Kovdor deposit: development conditions}

The Kovdor complex baddeleite-apatite-magnetite deposit was discovered in 1933; and in 1962 the Kovdorsky mining and processing enterprise started working. The Kovdorsky GOK has produced magnetite concentrate [2].

The physical-mechanical properties of rocks are closely related to their petrographic features. Based on this fact, the specialists of the VIOGEM Institute have divided all the 
geological formations of the Kovdor deposit into 6 lithotypes: metamorphic; hyperbasites; alkaline rocks; apatite-silicate-magnetite ores; apatite-carbonate-magnetite ores and carbonatites; and rocks of the disintegration zone.

All lithotypes, excluding the latter, belong to very strong (with uniaxial compressive strength $\left.\sigma_{\text {compr. }}>120 \mathrm{MPa}\right)$ or strong $\left(\sigma_{\text {compr. }}=50-120 \mathrm{MPa}\right)$ rocks, although hypogenic changes in rocks significantly reduce their strength. Only the intensive disintegration zone contains mainly hard medium-strength soils $\left(\sigma_{\text {compr. }}=15-50 \mathrm{MPa}\right)$, low-strength $\left(\sigma_{\text {compr. }}=\right.$ $5.0-15 \mathrm{MPa})$ and semi-hard $\left(\sigma_{\mathrm{compr}}<5.0-15 \mathrm{MPa}\right)$, as well as loose soils, which together form the 6th litotype [4].

At the present time, the Zhelezny open pit is developing complex baddeleite-apatitemagnetite and low-iron-apatite ores and is starting a francolitic (apatite-shtafelyte) and carbonatite deposit. In addition, since 1995 a mining-induced processing waste deposit has been developed. The deposit was formed in 1962-80 and contains industrial concentrations of apatite and baddeleite [3]. Over the past operating decades, the open pit has deepened up to more than $600 \mathrm{~m}$ from the maximum elevations of the original relief.

The Zhelezny open pit mine is exposed to failures such as rockfalls and slides of fractured and disintegrated rocks, landslides, wedge (prismatic) failures, plane failures, and combined failures [3].The first group is the most frequent and least dangerous in terms of ensuring the slope stability. Its occurrence is determined by the presence of intense fracturing areas and/or not enough high-quality technology of constructing benches into the final open pit outline.

The landslides develop mainly in the zone of surface disintegration of hard rocks in the upper part of the open pit (up to 100-120 m from the surface). Surface and ground water takes an active part in their formation. The deformation develops for a long time, sometimes for months, and can cover huge volumes of rock mass. The movements preceding the failure can reach tens of meters.

Deformations such as wedge (prismatic) failures are formed due to the reciprocal undercutting of two or more weakening surfaces (cracks, faults), the crossing line of which is inclined towards the open pit excavation. A failure prism bounded by these surfaces and the slope has a wedge shape. The development of large-scale deformations of this type represents a real danger to the stability of the slope or group (2-3) of the slopes [3]. A plane failure is the rock displacement towards the pit excavation along an inclined surface, formed by a crack, subparallel or close along the strike of a slope. This is the most dangerous type of failure, as it can cause a violation of the stability of not only a slope (group of slopes), but also of the all pit wall [3].

It is interesting to note that in the case of a wedge or plane failure, the previous rock mass deformation is visually hardly noticeable. The previous displacements of the rock mass reach values from a tenth of a millimeter to several centimeters. The period from the beginning of the rock mass deformation to a failure can fit into 2-3 hours. Such a variety types and scales in rock mass failures require applying an integrated approach to monitor the slope stability.

\subsection{The regional monitoring of the slope stability at the Zhelezny open pit}

To implement the regional monitoring of the slope stability at the Zhelezny open pit, there was constructed an optical distance testing site in 2006 [6]. Figure 1 shows the map of the location of the fundamental reference points of the optical distance chain. 


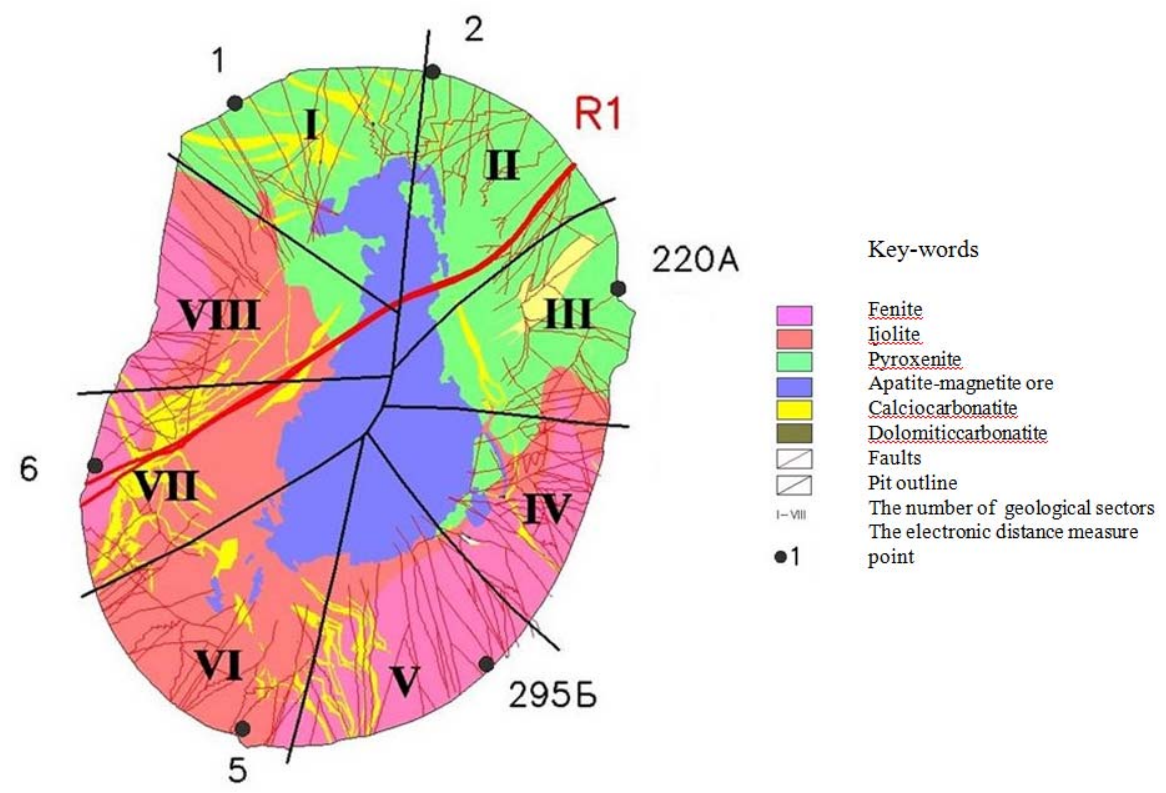

Fig. 1 - The map of the location of the fundamental reference points of the optical distance chain in the Zhelezny open pit mine, taking into account the zoning according to engineering-geological conditions [4].

The locations of the fundamental reference points were chosen taking into account the spatial location of large structural heterogeneities within the pit, in accordance with the current layout of large structural heterogeneities. When selecting the location of the points, specialists also took into account the conditions for ensuring direct visibility between points, the access roads and the convenience of approaching them [4].

Since 2006, regular slope stability observations were carried out, the optical distance measurement method was taken as the main one in the geodetic monitoring for the pit walls conditions. Since 2007, in addition to optical distance measurements, the specialists have begun measurements using satellite geodesy methods. Analysis of GPS measurements data for 2007-2017 and their comparison with the results of traditional geodetic measurements showed that satellite geodesy methods can be considered as the main ones and traditional geodesy methods - as additional which can be used in cases requiring increased accuracy and reliability of the results obtained. During the entire test site functioning, about 20 series of measurements were carried out. The general tendency of changing the distances between points, nearly always in all cycles, consisted in their decrease, i.e. the specialists observed the approaching of the pit walls. The maximum values of approaching were observed in the southern part of the open pit outline and amounted to about $300 \mathrm{~mm}$.

In 2015 , in order to clarify the boundaries of the identified structural and geological sectors and the size of the influence area of the open pit on the state of the surrounding rock massif, the main optical distance testing site in the Zhelezny open pit was supplemented with points that form an outer ring in relation to the fundamental points. Figure 2 shows a general scheme of the fundamental points' location. 


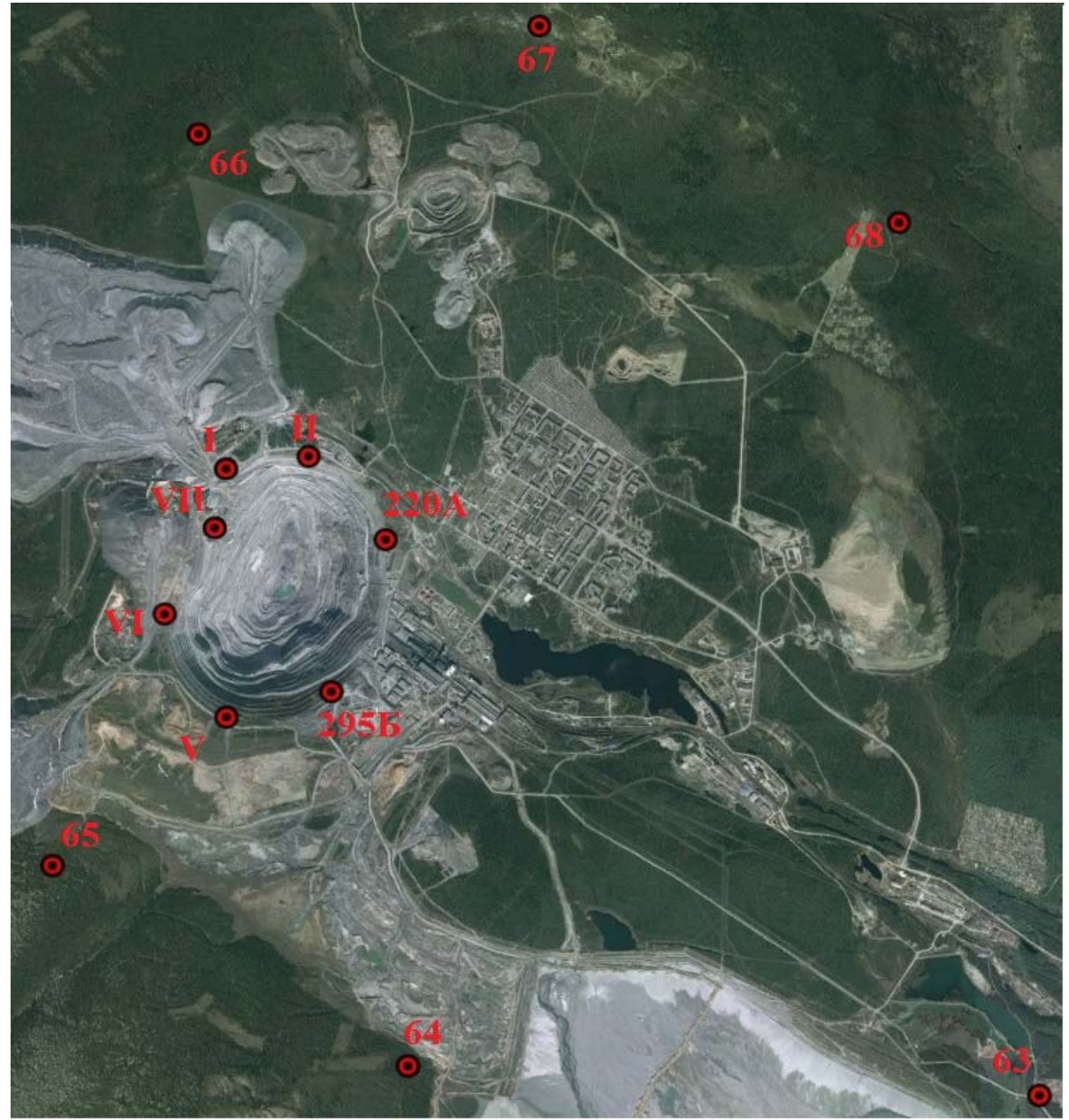

Fig. 2. The map of the fundamental points of the geomechanical testing site, Zhelezny mine, Kovdorsky GOK JSC.

Since 2016, the open pit has begun to expand. The points of the optical distance testing site (inner ring) were destroyed, with the exception of point $220 \mathrm{~A}$, however, the results obtained allowed the open pit to be conditionally zoned by the nature of the observed displacements to the northern and southern sections, and the separation boundary was the R1 fault (Figure 1). It is quite possible that the displacements observed in the southern section could have a negative impact on the stability of individual benches and provoke a series of failures in the underlying levels. To this date, the testing site is being restored.

\subsection{The local monitoring of the slope stability at the Zhelezny open pit.}

The ground-based interferometric radars are the most effective instruments of local monitoring, considering the physical-mechanical properties of the Kovdor deposit rocks and the variety of failures.

The main advantage of radars compared to other monitoring systems is the high measurement accuracy $(0.1 \mathrm{~mm}$ in ideal conditions) and the ability of 24-hour monitoring of the rock mass in any weather, regardless of precipitation (snow, rain, hail, fog) or bad visibility in the open pit caused by dust, exhaust fumes, etc. In 2001, GroundProbe Company released the first series of interferometric radars, and from this point on, the use 
of these technologies for monitoring in open pits began to increase. The radar manufacturers are Reutech Mining (South Africa), Ground Probe (Australia) and IDS (Italy). The radar operation principle is based on measuring the distance from a radio source to a monitored object. All existing radars differ in range (maximum range of $5000 \mathrm{~m}$ ), viewing angles, and pixel size (characterizes the degree of detail of the monitored rock mass). At the same time, the maximum permissible environmental conditions (for air: temperature, pressure, humidity, etc.) are almost identical for all types of radar (for example, the temperature difference is from -50 to +50 ). Radars are installed stationary or on mobile platforms. At the moment they are actively used in many foreign deposits, but in Russia the first radars appeared relatively recently.

In 2014, JSC Kovdorsky GOK installed 2D IBIS FM synthesized aperture radar made by IDS in a container version on the open pit outline of the Zhelezny mine. The action range is from 10 to 4,000 meters. The pixel size is $4.4 \mathrm{~m}$ at $0.75 \mathrm{~m}$ (at a distance of 1,000 $\mathrm{m}$ ) and $8.8 \mathrm{~m}$ at $0.75 \mathrm{~m}$ (at a distance of 2,000 m) [5 - 8]. At the moment, the number of interferometric radars has increased to 3 units. In 2019, the IBIS Rover radar was installed, and in 2020, the IBIS ArcSAR. Considering the technical capabilities of all three radars (maximum ranges, surveying angles, detailing), it became possible to simultaneously monitor all sections of the open pit wall.

In 2019, within the Project "Geo-Bio Hazards in the Arctic Region" under the European Neighbourhood Instrument Cross-Border Cooperation Programme Kolarctic 2014-2020, jointly with Finnish experts from GTK, Finland, we collected and analyzed the IBIS FM radar data on failures taking place in the Zhelezny open pit. Over the entire observation period, several failures on the scale of 1-2 benches and one large failure with a volume of about $100000 \mathrm{~m} 3$ were recorded.

Figure 3 shows a graph of the development of the landslide deformation process over time, which stretched for almost 7 months, and the maximum displacement of the observed area exceeded $2400 \mathrm{~mm}$.

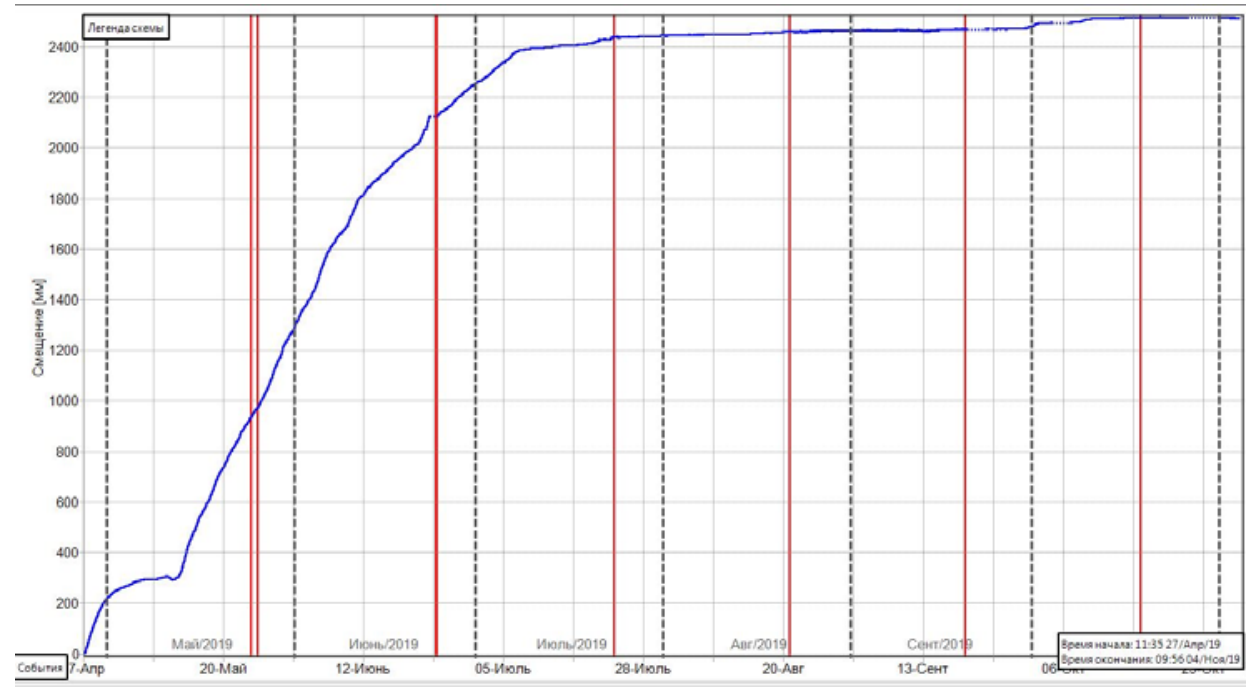

Fig. 3. Development of the deformation process of the rock mass during landslide failure according to the IBIS FM radar data.

Figure 4 shows an example of a graph of the development of wedge-type failure in time. 


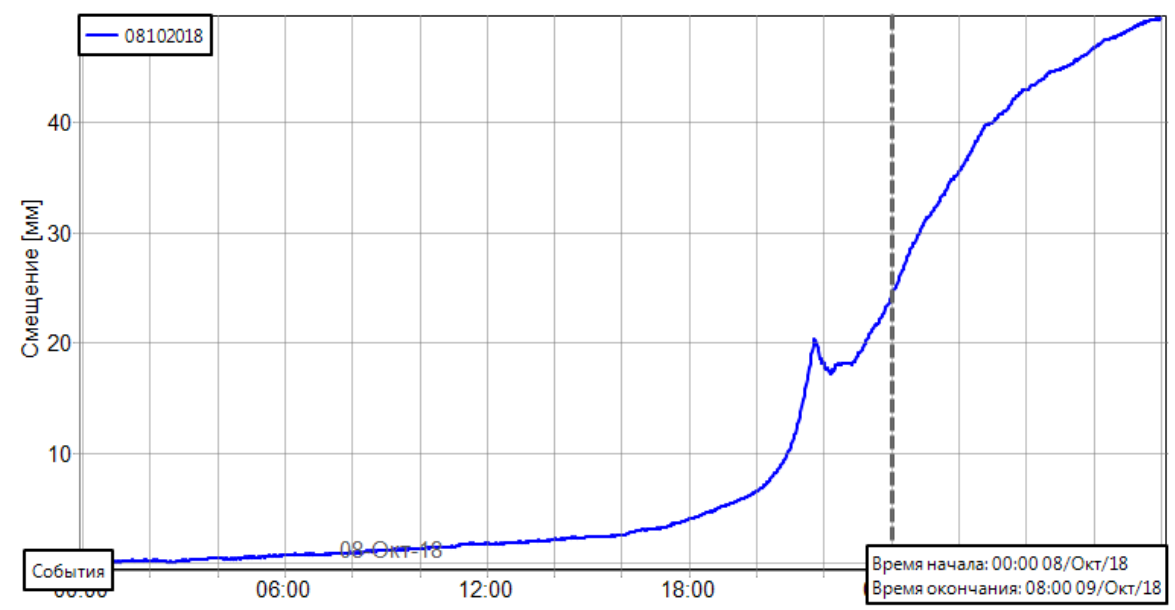

Fig. 4. Development of the deformation process of the rock mass with wedge-type failure according to the data of the IBIS FM radar.

The failure process was faster than the landslide process, and the maximum displacement was $52 \mathrm{~mm}$. The failure volume was approximately $100 \mathrm{~m}^{3}$.

\section{Conclusions}

1. The organized slope stability monitoring system for the Zhelezny open pit covers all types of failures occurring in the Kovdor high-strength rock mass such as landslides and various rockfalls.

2. The results of the GPS and optic distance measurements made it possible to zone the open pit by the nature of the observed movements to the northern and southern sections and to identify the area for local monitoring. Currently, the works are underway to restore the testing site for further observations of the open pit walls stability as a whole.

3. During the operation of the integrated monitoring system in the Zhelezny open pit, significant statistical material was accumulated, which made it possible to identify the regularities of the rock mass deformation development, to determine the limiting parameters and to develop «Methodological recommendations for the application of space geodesy methods for geomechanical monitoring of hard rock massifs during open pit mining» and «Interim instruction for monitoring deformations of the open pit walls and benches using the IBIS FM radar».

This publication has been produced with the assistance of the European Union. The contents of this publication are the sole responsibility of the following authors: Anatolii Kozyrev Eduard Kasparian and Ivan Rozanov and can in no way be taken to reflect the views of the European Union.

\section{References}

1. I.Yu. Rozanov, A.A. Zavyalov, Topical Issues of Rational Use of Natural Resources, 1, $476(2019)$

2. V.A. Dunaev, S.S. Seryj, A.V. Gerasimov, S.N. ZHurin, A.N. Byhovec, B.V. Slavskij, Gornyj zhurnal, 4, 41 (1998)

3. A.A. Zavyalov, Subsurface management problems. Materials of the VI Russian Youth Scientific and Practical Conference, 292 (2012) 
4. I.YU. Rozanov, R.N. Dostovalov, M.A. Kuznecov, GIAB, 11 (56), 183 (2015)

5. I.YU. Rozanov, A.A. Zavyalov, GIAB, 7, 40 (2018)

6. H. Mitri, I. Vennes, Proceedings Mine Planning and Equipment Selection (2014)

7. M. Pieraccini, Proceedings Progress In Electromagnetics Research Symposium Proceedings (2013)

8. P. Farina, L. Leoni, F. Babboni, F. Coppi, L. Mayer, P. Ricci, Proceedings, Slope Stability 2011: International Symposium on Rock Slope Stability in Open Pit Mining and Civil Engineering (2011) 